\title{
Interatrial block as electrocardiographic predictive sign for atrial fibrillation in patients hospitalized in Internal Medicine Departments
}

\author{
Gianpaolo Bragagni, Chiu Hua Chen, Federico Lari, Gaetano Magenta \\ Department of Medicine, SS Salvatore Hospital, AUSL Bologna, S. Giovanni in Persiceto (BO), Italy
}

\begin{abstract}
This study evaluated the correlation between interatrial block (IAB) and atrial fibrillation (AF) among patients admitted to our Internal Medicine Unit: 110 (group 1) were identified with electrocardiograms both in sinus rhythm and AF, and 123 (group 2) constantly in sinus rhythm. In both groups we analyzed: the presence of partial $(\mathrm{P} \geq 120 \mathrm{msec})$ or advanced ( $\mathrm{P}>120 \mathrm{msec}$ and biphasic in D2, D3, aVF) IAB, and the main electrocardiographic and clinical features. Age and gender between the two groups were similar. IAB was present in $89 / 110(80.91 \%)$ in group 1 and $26 / 123(21.13 \%)$ in group $2(\mathrm{P}=<0.01)$; partial in $50 / 110$ $(45.45 \%)$ and 19/123 (15.7\%) in group 1 and 2 respectively $(\mathrm{P}<0.01)$, advanced in 39/110 (35.45\%) and 7/123 (5.69\%) $(\mathrm{P}<0.019)$. The correlation between IAB and AF was significant $(\mathrm{P}<0.001)$; $36(65.4 \%)$ patients out of 55 with atrial echo dilatation had IAB and 14 (25.4\%) had deep terminal negativity of P-wave in V1 (DTNPV1) $>0.1 \mathrm{mV}(\mathrm{P}<0.01)$. IAB represents a reliable predictor of AF; moreover, the sensitivity of the IAB in detecting atrial dilatation is higher than the DTNPV1 $>0.1 \mathrm{mV}$.
\end{abstract}

\section{Introduction}

Several articles in scientific literature have shown an association of some kind between intra-atrial block (IAB) and the onset of tachyarrhythmias, in particular atrial fibrillation and/or flutter. ${ }^{1-4}$ The IAB, which reflects a conduction delay in the Bachmann's bundle, ${ }^{5,6}$ creates an arrhythmogenic substrate that predisposes for sustained arrhythmias. ${ }^{7-9}$ The partial

Correspondence: Gianpaolo Bragagni, Department of Medicine, SS Salvatore Hospital, AUSL Bologna, S. Giovanni in Persiceto (BO), Italy.

Tel.: +39.0516813230. E-mail: gianbra@iol.it

Key words: Interatrial block; Bachmann's bundle; atrial fibrillation; deep terminal negativity of P-wave in V1.

Contributions: GB designed the work, collected the cases, analyzed the electrocardiograms, wrote the manuscript; $\mathrm{CCH}$, FL and GM analyzed the electrocardiograms and revised the manuscript.

Conflict of interests: the authors declare no conflict of interests.

Received for publication: 14 January 2019.

Revision received: 28 February 2019.

Accepted for publication: 28 February 2019.

This work is licensed under a Creative Commons Attribution NonCommercial 4.0 License (CC BY-NC 4.0).

CCopyright G. Bragagni et al., 2019

Licensee PAGEPress, Italy

Italian Journal of Medicine 2019; 13:103-108

doi:10.4081/itjm.2019.1134
IAB is characterized by a $\mathrm{P}$-wave duration of $\geq 120$ $\mathrm{ms}$, while the advanced IAB presents a duration of the $\mathrm{P}$-wave $\geq 120 \mathrm{~ms}$ and a biphasic pattern in leads II, III and aVF (Figure 1). The positive/negative morphology of $\mathrm{P}$-wave in the inferior leads is due to a retroactivation, caudocranial, of the left atrium. ${ }^{1}$

Some reports have shown a correlation between the presence of IAB with the onset of cryptogenicconsidered ischemic strokes. ${ }^{10,11}$

Nevertheless, IAB is still largely ignored or underestimated in clinical practice, so much that it nearly never appears in ordinary electrocardiogram (ECG) reports and it is never reported by automatic ECG machines.

Moreover many studies suggested that there are other valid electrocardiographic characteristics that can predict the onset of atrial fibrillation: the dispersion of the P-wave, ${ }^{12,13}$ the duration (which in this case is comparable to a IAB anyway), ${ }^{14-16}$ the variability, ${ }^{17}$ the $\mathrm{V} 1$ terminal negativity longer than $40 \mathrm{msec},{ }^{18,19}$ the PR interval, ${ }^{20,21}$ the extrasystolic burden, ${ }^{22,23}$ the $\mathrm{Tp} / \mathrm{Te}$ interval $\leq 90 \mathrm{msec}^{24}$

Actually P-wave alterations predictive value appears still uncertain and not universally accepted. Some studies have discredited its real value and its contribution to risk stratification. ${ }^{25,26}$

The aim of this retrospective and observational study was to evaluate the correlation between the presence of IAB and the onset of atrial flutter and/or fibrillation in a population of hospitalized patients with several risk factors.

Furthermore, the aim was to compare the prevalence of IAB between the group of patients who developed arrhythmic episodes and the control group of patients who did not show arrhythmic events but who had similar risk factors. 
Age, and age-associated comorbidities have been considered in both groups, as well as ECG parameters that can, according to literature, possibly predict an evolution towards sustained atrial arrhythmias, in order to detect the predictive significance of arrhythmic events of the above-mentioned elements, to compare them and to evaluate the possible usefulness of a conjunct consultation.

\section{Materials and Methods}

This study was approved by the Bologna-Imola inter-company ethics committee (EC 17168, protocol number 150935, approved on 20/12/2017).

We analyzed the medical records, scanned and stored in our electronic health records, of the patients of our Unit of Internal Medicine in a time frame of 30 months (years 2015, 2016 and first six months of 2017). In particular we used some key words as search filters among the discharge diagnosis of the patients: heart failure, supraventricular arrhythmias, arterial hypertension, ischemic cardiopathy, primitive cardiomyopathies, valvulopathies, respiratory failure.

Besides, we selected the patients who had an alternation of sinus rhythm and atrial fibrillation that is when an ECG of both sinus rhythm and atrial fibrilla-

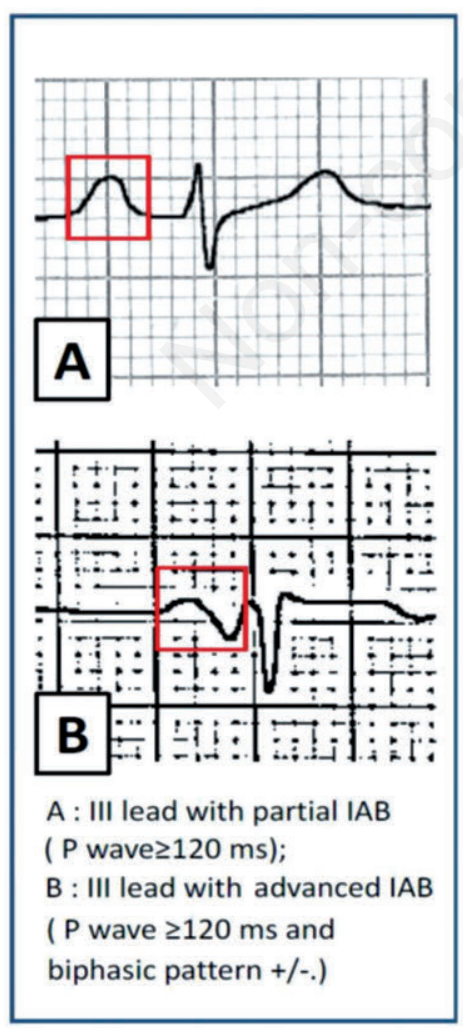

Figure 1. Interatrial block. tion was available. Of such patients we registered in an appropriate database: sex, age, ECG parameters (presence and degree of IAB, duration, dispersion of $\mathrm{P}$-wave, presence of extrasystoles, PR interval, deep terminal negativity of $\mathrm{P}$-wave in $\mathrm{V} 1$, presence of ventricular hypertrophy, bundle branch blocks and hemiblocks, Tpeak/Tend interval), and atrial dimensions.

We also considered the following comorbidities: arterial hypertension, ischemic cardiopathy, valvulopathies, primitive cardiomyopathies, heart failure, stroke, respiratory failure-chronic obstructive pulmonary disease (COPD), diabetes mellitus, kidney failure (with $1.5 \mathrm{mg} / \mathrm{dL}$ or more of creatinine), dyslipidemias, obesity, anemia (10 g/dL or lower hemoglobin), dysthryoidisms, dementia.

The analysis of the ECG parameters has been elaborated on the digital electrocardiograms (scanned at 600 DPI), which allowed us to zoom in and to accurately measure and evaluate them. Unreadable and not clear enough ECGs were discarded. Each graph has been manually analyzed and reported, with particular attention to the P-wave, by two authors separately and, in case of different reports between the two of them, the analysis was performed by a third author.

IAB, according to the 2012 Consensus Report, ${ }^{1}$ was diagnosed as partial if the P-wave lasted $\geq 120$ msec and advanced if - other than such duration - positive/negative biphasic P-waves appearance in lead II, III and aVF was present; maximum P-wave duration was defined as the longest duration $\mathrm{P}$-wave (in $\mathrm{msec}$ ) from all leads; $\mathrm{P}$ wave dispersion was defined as the difference between the maximum and minimum Pwave durations; the PR interval, in milliseconds, was defined by measurement from the onset of the P-wave to the initiation of the $\mathrm{QRS}$. The presence of deep terminal negativity of P-wave in $\mathrm{V} 1 \geq 0.1 \mathrm{mV}$ (DTNPV1 $\geq 0.1 \mathrm{mV}$ ) was established if the amplitude of the terminal negative phase of $\mathrm{P}$-wave in lead V1 exceeded $0.1 \mathrm{mV}=1 \mathrm{~mm}$. Left bundle branch block (LBBB) was defined by a prolonged QRS duration of $\geq 0.12$ sec associated with a broad, notched $\mathrm{R}$ wave without q waves in leads I, aVL, and V6, and an rS pattern in lead V1. Right bundle branch block (RBBB) was characterized by prolonged QRS duration of $\geq 0.12$ sec, associated with an R, rSR', or qR wave in lead V1 appearance; wide, slurred $\mathrm{S}$ waves in leads I, aVL, $\mathrm{V} 5$, and V6 and a wide terminal $r$ wave in aVR. Left anterior hemiblock (LAH) was defined by leftward axis deviation of $-30^{\circ}$ or more associated with $\mathrm{qR}$ wave in leads I and aVL and an rS pattern in leads II, III, and aVF. The following measurements were used to define left ventricular hypertrophy (LVH): Sokolow-Lyon voltage (SV1+max RV5/V6) $\geq 35 \mathrm{mV}$; Cornell voltage $(\mathrm{SV} 3+\mathrm{RaVL}) \geq 2.8 \mathrm{mV}$ (males) or $\geq 2.2 \mathrm{mV}$ (females).

The extrasystolia was defined by the presence of 
at least one ventricular or supraventricular extrasystole in the examined graph.

The Tp-Te interval was defined as the interval from the peak of $\mathrm{T}$ wave to the end of $\mathrm{T}$ wave. Measurements of Tp-Te interval were performed from precordial leads.

The presence of comorbidities was deduced by the information on the medical reports and laboratory exams. We considered as anemic those patients with less than $10 \mathrm{~g} / \mathrm{dL}$ of hemoglobin in at least two inspections, and we considered kidney failure for patients with $\geq 1.5 \mathrm{mg} / \mathrm{dL}$ of creatinine.

The same elements were analyzed in another similarly sized group of patients who were constantly in sinus rhythm, recruited among the patients hospitalized in our department during the same period of time, using the same search filters, but excluding the ones who had arrhythmic events even in the past.

By comparing the two groups we established the prevalence of IAB and its correlation with atrial fibrillation and the other examined elements, and that the difference between the groups was statistically significant. In those cases when an echocardiogram was available, we also evaluated the sensitivity and specificity of both the IAB and the DTNPV1 in reports of left atrium dilatation. At the echocardiographic examination the left atrium was considered dilated if, in the unidimensional study, it was superior to $40 \mathrm{~mm}$ of antero-posterior diameter in the parasternal long axis approach.

Mean and standard deviations of age and sex were calculated and compared in the two groups. The Chisquare test was used to compare data from the control group and from patients with atrial fibrillation $(\mathrm{AF}) /$ Flutter and to compare the frequency of IAB and DTNPV1 $>0.1 \mathrm{mV}$ in patients with echocardiographically-demonstrated left atrial dilatation. A P value $<0.05$ was considered statistically significant. Pearson's correlation coefficient was used to evaluate the significance of the correlation between IAB and AF.

\section{Results}

Out of the 4361 clinical records of the patients hospitalized in the Internal Medicine Unit of S. Giovanni in Persiceto hospital (Bologna), during a time span of 30 months (from January $1^{\text {st }} 2015$ to June $30^{\text {th }} 2017$ ), 1120 were analyzed using the search filters mentioned above. Among these, 110 patients have been individuated and they had both sinus rhythm and atrial fibrillation and/or flutter in their ECGs (Group 1) and 123 patients with similar characteristics but constantly in sinus rhythm (Group 2). Only six electrocardiograms out of 1120 were excluded because of poor quality or illegibleness.

The average ages in group 1 and group 2 were respectively $80.7 \pm 9.0$ and $81.3 \pm 12,36.36 \%$ vs $44.71 \%$ men and $63.64 \%$ vs $55.28 \%$ women. IAB was present in 89 patients $(80.91 \%)$ belonging to group 1 , and in 26 patients $(21.13 \%)$ included in group 2 . IAB was partial in 50/110 (45.45\%) and in 19/123 (15.47\%), advanced in $39 / 110(35.45 \%)$ and in $7 / 123(5.69 \%)$ in the two groups respectively. These data, along with other ECG parameters (P-wave dispersion $\geq 50 \mathrm{msec}, \mathrm{P}$-wave duration $\geq 110 \mathrm{msec}, \mathrm{PR} \geq 200 \mathrm{msec}$, occurrence of extrasystoles, DTNPV $\geq 0.1 \mathrm{mV}, \mathrm{Tp} / \mathrm{Te} \leq 90 \mathrm{msec}, \mathrm{LVH}$, LBBBs, RBBBs, LAH) and the statistical significance of the difference between the two groups are summarized in Table 1. The significant differences that emerged between the two groups are the frequency of $\mathrm{IAB}$, for both the partial and the advanced form - thus globally - and the dispersion of the P-wave $\geq 50 \mathrm{msec}$, the $\mathrm{P}$-wave duration $\geq 110 \mathrm{msec}$ and the $\mathrm{LVH}$.

Table 2 summarizes the many clinical entities that were analyzed in both groups: hypertension, heart failure, ischemic cardiopathy, valvulopathies, respiratory failure/COPD, stroke or transient ischemic attack, diabetes mellitus, dyslipidemias, obesity, anemia, dysthryoidisms, dementia. Only heart failure, ischemic cardiopathy and valvulopathies resulted as significantly different between the two groups.

In the 233 total patients, the correlation between IAB and FA was significant: $\mathrm{r}=0.598(\mathrm{P}<0.001)$.

An echocardiographic measurement of left atrium

Table 1. Electrocardiographic characteristics of patients with atrial fibrillation/atrial flutter (Group 1) and in sinus rhythm (Group 2).

\begin{tabular}{lccc}
\hline Patients & Group 1 (n=110) & Group 2 (n=123) & P \\
\hline Age & $80.7 \pm 9.0$ & $81.3 \pm 12$ & NS \\
\hline Women & $70(63.69 \%)$ & $68(55.28 \%)$ & NS \\
\hline IAB & $89(80.9 \%)$ & $26(21.1 \%)$ & $<0.01$ \\
\hline IAB partial & $50(45.4 \%)$ & $19(15.4 \%)$ & $<0.01$ \\
\hline IAB advanced & $39(35.4 \%)$ & $7(5.6 \%)$ & $<0.01$ \\
\hline P dispersion $\geq 50 \mathrm{msec}$ & $67(60.9 \%)$ & $41(33.3 \%)$ & $<0.01$ \\
\hline P duration $\geq 110 \mathrm{msec}$ & $97(88.1 \%)$ & $30(24.3 \%)$ & $<0.01$ \\
\hline PR $\geq 200 \mathrm{msec}$ & $26(23.6 \%)$ & $33(26.8 \%)$ & $\mathrm{NS}$ \\
\hline Extrasistolia & $23(20.9 \%)$ & $23(18.6 \%)$ & $\mathrm{NS}$ \\
\hline DTNPV1 $\geq 0.1 \mathrm{mV}$ & $24(21.8 \%)$ & $31(25.2 \%)$ & $\mathrm{NS}$ \\
\hline Tp-Te $\leq 90 \mathrm{msec}$ & $59(53.6 \%)$ & $58(47.1 \%)$ & $\mathrm{NS}$ \\
\hline LVH & $28(25.4 \%)$ & $15(12.1 \%)$ & $<0.01$ \\
\hline RBBB & $12(10.9 \%)$ & $23(18.6 \%)$ & $\mathrm{NS}$ \\
\hline LBBB & $20(18.1)$ & $16(13.0 \%)$ & $\mathrm{NS}$ \\
\hline LAH & $10(9.0 \%)$ & $18(14.6 \%)$ & $\mathrm{NS}$ \\
\hline
\end{tabular}

NS, not significant $(\mathrm{P}>0.05)$; IAB, interatrial block; DTNPV $\geq 0.1 \mathrm{mV}$, deep terminal negativity of P-wave in $\mathrm{Vl} \geq 0.1 \mathrm{mV}$; TpTe, Tpeak/Tend interval; $\mathrm{LVH}$, left ventricular hypertrophy; RBBB, right bundle branch block; LBBB, left bundle branch block; LAH, left anterior hemiblock. 
was reported in only 70 patients, 52 patients from group 1 and 18 from group 2: among them, 40/52 $(76.92 \%)$ in the first group and $15 / 18(83.3 \%)$ in the second group had atrial dilatation, while 12/52 $(23.07 \%)$ in group 1 and 3/18 (16.66\%) in group 2 had normally sized atria. Figure 2 shows the 55 patients, cumulative of the two groups, with atrial dilatation: $36(65.4 \%)$ had IAB in the ECG (18 partial and 18 complete), but only 14 (25.4\%) had DTNPV1 $\geq 0.1 \mathrm{mV}$ $(\mathrm{P}<0.01)$.

\section{Discussion}

Previous studies have evaluated the frequency of development of atrial fibrillation in patients with IAB. However, in this study we identified the patients who had AF and then we analyzed how many of them had IAB in their sinus rhythm ECGs. Since AF is a condition that can be determined by different diseases, we wanted to show the possible role of the IAB in creating an arrhythmogenic substrate, and its clinical relevance.

The results of our analysis showed a strong correlation between atrial fibrillation and/or flutter and the presence of IAB, both partial and complete, outstandingly superior to the one reported in the control group. Such correlation, already reported in some contributions, in our study appeared very strong, and particularly relevant is the frequency of complete $\mathrm{IAB}$ compared to partial IAB. Both the strong IAB/AF correlation and the high percentage of complete IAB could be a reflection of the composition of the analyzed populations: acute hospitalized patients in an in-

Table 2. Clinical characteristics of patients with atrial fibrillation/atrial flutter (Group 1) and in sinus rhythm (Group 2).

\begin{tabular}{lccc}
\hline Patients & Group 1 (n=110) & Group 2 (n=123) & P \\
\hline Hypertension & $75(68.1 \%)$ & $75(60.9 \%)$ & NS \\
\hline Coronary artery disease & $36(32.7 \%)$ & $26(21.1 \%)$ & 0.04 \\
\hline Valvular heart disease & $22(20 \%)$ & $12(9.7 \%)$ & 0.02 \\
\hline Heart failure & $73(66.3 \%)$ & $48(39.0 \%)$ & $<0.01$ \\
\hline Diabetes mellitus & $27(24.5 \%)$ & $44(35.7 \%)$ & NS \\
\hline Dyslipidemia & $27(24.5 \%)$ & $32(26 \%)$ & NS \\
\hline Prior stroke or TIA & $10(9.0 \%)$ & $16(13 \%)$ & NS \\
\hline COPD/respiratory failure & $38(34.5 \%)$ & $53(43 \%)$ & $\mathrm{NS}$ \\
\hline Obesity & $17(15.4 \%)$ & $13(10.5 \%)$ & $\mathrm{NS}$ \\
\hline Dementia & $37(33.6 \%)$ & $46(37.3 \%)$ & $\mathrm{NS}$ \\
\hline Anemia & $22(20 \%)$ & $34(27.6 \%)$ & $\mathrm{NS}$ \\
\hline Dysthyroidism & $20(18.1 \%)$ & $16(13.0 \%)$ & $\mathrm{NS}$ \\
\hline
\end{tabular}

NS, not significant $(\mathrm{P}>0.05)$; TIA, transient ischemic attack; COPD, chronic obstructive pulmonary disease. ternal medicine department, with a high mean age and several comorbidities, which is actually coherent with the real clinical world.

Previous studies regarding the prevalence of IABs among the patients hospitalized in a General Hospital population reported a very high prevalence of IAB $(32.8 \%)$, the mean age was 68.2 years in male patients and 71.7 in females. ${ }^{27}$ In the patients, we analyzed the prevalence, which was $49.35 \%$ (115/233), but the patients were selected for having cardiovascular problems. In addition to this, the patients with IAB were absolutely asymmetrically distributed: the majority of them later developed supraventricular arrhythmias.

Moreover, it should be kept in mind that some of the patients who had IAB and sinus rhythm could have likely had fibrillation attacks that remained unknown or could have developed AF later in time.

From the analyses conducted on the results of the atherosclerosis risk in communities (ARIC) study ${ }^{25}$ - one of the largest regarding this topic - only 69 out of 14,625 patients $(0.5 \%)$ had advanced IAB at the moment of recruitment, compared to the 48 out of 233 that we reported $(20.60 \%)$. Since in our study the patients were hospitalized, they were likely to be more morbid, and the average of age was over 80 years, while in the ARIC study they recruited patients from 45 to 64 years of age. The high percentage of complete IAB reported in our approximately octogenarian patients $(35.45 \%$ in the group with reported $\mathrm{AF} / \mathrm{Fl}$ and $5.69 \%$ in the constant sinus rhythm patients) is not really surprising: upon $0.5 \%$ reported by the ARIC study (average of age: 59), a study on centenarian patients recorded a prevalence of IABs of $26 \%$, with a higher frequency of advanced IAB than partial IAB $(20 \%) .^{28}$

The presence of $\mathrm{P}$-waves $\geq 110 \mathrm{msec}$ has also a significant correlation with $\mathrm{AF}$, resulting more sensitive than IAB but less specific: such observation appears obvious, since P-wave duration still represents the main characteristic of IAB, and the reduction - although very small - of the cut-off (from 120 to 110

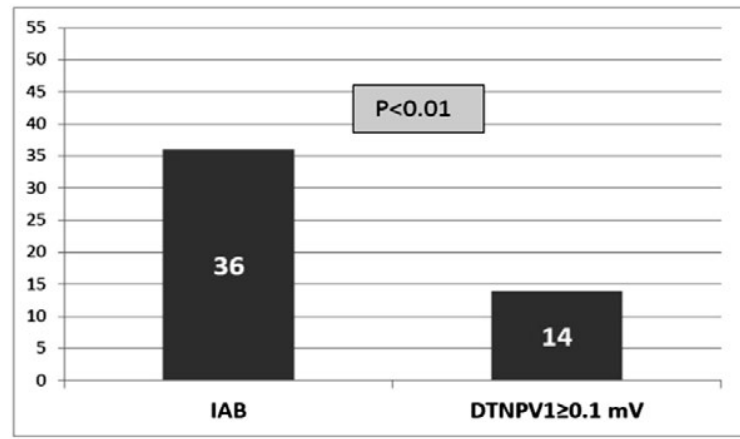

Figure 2. Patients with echocardiographic evidence of atrial dilatation $(\mathbf{n}=55)$. 
msec) can only widen the number of interested patients (from $80.9 \%$ to $88.1 \%$ ), but at the same time it reduces the specificity $(21.3 \%$ of patients in sinus rhythm in IAB, $24.3 \%$ in $P \geq 110 \mathrm{msec}$ ). Similarly, the $\mathrm{P}$-wave dispersion overlaps IAB, because the longest is the P-wave the highest is the probability of its distinct dispersion: as a matter of fact, both the sensitivity and the specificity appear clearly lower than the ones reported for IAB (IAB is present in $80.9 \%$ and the dispersion $\geq 50 \mathrm{msec}$ in $60.9 \%$ in the group with $\mathrm{AF}$, IAB is $21.3 \%$ and the dispersion $\geq 50 \mathrm{msec}$ is $33.3 \%$ in the control group).

On the other hand, the correlation with DTNPV1 $\geq 0.1 \mathrm{mV}$, which was reported with a higher frequency in the control group, appeared absolutely inconsistent. Similarly, the association with $\mathrm{Tp} / \mathrm{Te} \leq 90 \mathrm{msec}$ and with the presence of extrasystoles - equivalent in the two groups - resulted non-significant. The PR interval $\geq 200 \mathrm{msec}$ was only present in more or less one out of four patients in both groups and appeared to have a scarce predictive value for atrial fibrillation.

Left ventricular hypertrophy is significantly more frequent in the AF group compared to the control group, but with a low prevalence and a dubious predictive value. There are no significant differences between the two groups in the RBBB, LBBB and left anterior hemiblock prevalence.

Among the clinical correlations, the most significantly represented in the group of patients with $\mathrm{AF}$ were heart failure, valvulopathies, and ischemic heart disease.

This is not surprising because it reflects both the fact that the patients of that group were more compromised, and the hemodynamic deterioration that AF determines.

Hypertension is more frequent in group 1, with documented AF, than in group 2 in sinus rhythm, but this difference does not reach statistical significance $(68.1 \%$ vs $60.9 \%)$. In group 1, however, the prevalence of IAB is much higher than in group 2 (80.9\% $v s 21.1 \%$ ) and this seems to suggest that among hypertensive patients, those who develop an IAB are more predisposed to present an AF.

More interesting is the lack of significant differences between stroke and dementia prevalence in the two groups: this could be due to the fact that $\mathrm{AF}$ was mainly observed in its early stages, before the possible complications could become evident. Moreover, it is likely that this study was too underpowered to detect these associations.

Echocardiographically-determined atrial dilatation was present in the vast majority of patients in both groups, with no significant differences between them. The fact that the IAB associates more strictly with atrial dilatation rather than DTNPV1 $\geq 0.1 \mathrm{mV}$ is remarkable: IAB could be used with more reliability in ECG-based atrial dilatation diagnosis.

\section{Conclusions}

The ARIC study showed that the presence of IAB, even though relevant in the examined population, was not particularly useful in the prediction of AF onset compared to the presence of traditional risk factors. ${ }^{25}$ Vice versa, in our patients, the presence of traditional risk factors resulted similar in those with constant sinus rhythm and in those who had AF, while the IAB was distinctly more frequent in the $\mathrm{AF}$ group, appearing as a quite sensitive marker for arrhythmic risk. This disparity could at least partially be explained by the already mentioned different selection in the patients' recruitment method. However, in our study, the hospitalized patients with IABs should be considered with a high risk of developing AF: such consideration implies the necessity of a careful clinical and instrumental monitoring of these patients, in order to promptly detect the arrhythmic evolution. This involves clinical and electrocardiographic checks, including Holter recordings also prolonged, or the use of loop-recorder. It should also be considered that the IAB involves an electromechanical dysfunction capable of realizing the conditions suitable for the formation of thrombi, with or without the onset of arrhythmias. For the future, it is conceivable that IAB can help to identify a population at high risk of cardioembolic events, so as to deserve anticoagulant prophylaxis. Obviously, this possibility will have to be validated by solid studies that provide definitive evidence.

On the other hand, since the IAB is potentially reversible, a weighted therapy seems appropriate, especially for the conditions that are proven to be reversible (arterial hypertension, ${ }^{29}$ heart failure ${ }^{30}$ ).

\section{References}

1. Bayés de Luna A, Platonov P, Cosio FG, et al. Interatrial blocks. A separate entity from left atrial enlargement: a consensus report. J Electrocardiol 2012;45:445-51.

2. Enriquez A, Conde D, Redfearn DP, Baranchuk A. Progressive interatrial block and supraventricular arrhythmias. Ann Noninvasive Electrocardiol 2015;20:394-6.

3. Bayés de Luna A, Cladellas M, Oter R, et al. Interatrial conduction block and retrograde activation of the left atrium and paroxysmal supraventricular tachyarrhythmia. Eur Heart J 1988;9:1112-8.

4. van Campenhout MJ, Yaksh A, Kik C, et al. Bachmann's bundle: a key player in the development of atrial fibrillation? Circ Arrhythm Electrophysiol 2013;6:1041-6.

5. Bachmann $\mathrm{G}$. The significance of splitting of the P-wave in the ECG. Ann Intern Med 1941;14:1702-9.

6. Waldo AL, Bush HL Jr, Gelband H, et al. Effects on the canine $\mathrm{P}$ wave of discrete lesions in the specialized atrial tracts. Circ Res 1971;29:452-67.

7. Bayés de Luna A, Guindo J, Viñolas X, et al. Third-degree inter-atrial block and supraventricular tachyarrhythmias. Europace 1999;1:43-6. 
8. Censi F, Calcagnini G, Bartolini P. Fibrillazione atriale: analisi dell'onda P di superficie. Rapporti ISTISAN 08/13. Roma: Istituto Superiore di Sanità; 2008.

9. Goyal SB, Spodick D. Electromechanical dysfunction of the left atrium associated with interatrial block. Am Heart J 2001;142:823-7.

10. Lorbar M, Levrault R, Phadke J, Spodick, DH. Interatrial block as a predictor of embolic stroke. Am J Cardiol 2005;95:667-8.

11. Ariyarajah V, Apiyasawat S, Najjar H, et al. Frequency of interatrial block in patients with sinus rhythm hospitalized for stroke and comparison to those without interatrial block. Am J Cardiol 2007;99:49-52.

12. Dogan U, Dogan EA, Tekinalp M, et al. P-wave dispersion for predicting paroxysmal atrial fibrillation in acute ischemic stroke. Int J Med Sci 2012;9:108-14.

13. Boriani G, Diemberger I, Biffi M, et al. P wave dispersion and short-term vs. late atrial fibrillation recurrences after cardioversion. Int J Cardiol 2005;101:355-61.

14. Dilaveris PE, Gialafos EJ, Sideris SK, et al. Simple electrocardiographic markers for the prediction of paroxysmal idiopathic atrial fibrillation. Am Heart J 1998;135: 733-8.

15. Magnani JW, Johnson VM, Sullivan LM, et al. P wave duration and risk of longitudinal atrial fibrillation in persons $\geq 60$ years old (from the Framingham Heart Study). Am J Cardiol 2011;107:917-21.

16. Nielsen JB, Kühl JT, Pietersen A, et al. P-wave duration and the risk of atrial fibrillation: Results from the Copenhagen ECG Study. Heart Rhythm 2015;12:1887-95.

17. Censi F, Corazza I, Reggiani E, et al. P-wave variability and atrial fibrillation. Sci Rep 2016;6:26799.

18. Magnani JW, Williamson MA, Monahan KM, et al. P Wave indices: current status and future directions in epidemiology, clinical and research applications. Circ Arrhythmia Electrophysiol 2009;2:72-9.

19. Tereshchenko LG, Henrikson CA, Sotoodehnia N, et al. Electrocardiographic deep terminal negativity of the $p$ wave in V1 and risk of sudden cardiac death: the atherosclerosis risk in communities (ARIC) study. J Am Heart Assoc 2014;3:e001387.
20. Nielsen JB, Pietersen A, Graff C, et al. Risk of atrial fibrillation as a function of the electrocardiographic PR interval: results from the Copenhagen ECG Study. Heart Rhythm 2013;10:1249-56.

21. Bidstrup S, Olesen MS, Svendsen JH, Nielsen JB. Role of PR-interval in predicting the occurrence of atrial fibrillation. J Atrial Fibril 2013;6:90-4.

22. Capucci A, Santarelli A, Boriani G, Magnani B. Atrial premature beats coupling interval determines lone paroxysmal atrial fibrillation onset. Int $\mathrm{J}$ Cardiol 1992;36:87-9.

23. Varounis C, Dagres N, Maounis T, et al. Atrial premature complexes and heart rate have prognostic significance in 1-month atrial fibrillation recurrence after electrical cardioversion. Europace 2007;9:633-7.

24. Bachmann TN, Skov MW, Rasmussen PV, et al. Electrocardiographic Tpeak-Tend interval and risk of cardiovascular morbidity and mortality: results from the Copenhagen ECG study. Heart Rhythm 2016;13:915-24.

25. Magnani JW, Zhu L, Lopez F, et al. P-wave indices and atrial fibrillation: cross-cohort assessments from the Framingham Heart Study (FHS) and Atherosclerosis Risk in Communities (ARIC) study. Am Heart J 2015; 169:53-61.

26. Ariyarajah V, Fernandes J, Kranis M, et al. Prospective evaluation of atrial tachyarrhythmias in patients with interatrial block. Int J Cardiol 2007;118:332-7.

27. Jairath UC, Spodick DH. Exceptional prevalence of interatrial block in a general hospital population. Clin Cardiol 2001;24:548-50.

28. Martínez-Sellés M, Massó-van Roessel A, Álvarez-García $\mathrm{J}$, et al. Interatrial block and atrial arrhythmias in centenarians: prevalence, associations, and clinical implications. Heart Rhythm 2016;13:645-51.

29. Celik T, Iyisoy A, Kursaklioglu H, et al. The comparative effects of telmisartan and ramipril on P-wave dispersion in hypertensive patients: a randomized clinical study. Clin Cardiol 2005;28:298-302.

30. Proietti R, Mafrici A, Spodick DH. Dynamic variations of P-wave duration in a patient with acute decompensated congestive heart failure. Cardiol J 2012;19:95-7. 